\title{
A Context-Based Perspective to Investigating the Construct Validity of Reading Assessments
}

\author{
Dr. Godefroid B. Katalayi \\ University of the Western Cape, South Africa \\ bkatalayi@uwc.ac.za
}

Prof. Sivakumar Sivasubramaniam

University of the Western Cape, South Africa sivakumar49@hayoo.com

\section{Doi:10.5901/mjss.2014.v5n27p847}

\begin{abstract}
The paper examines the construct validity of a high stake multiple-choice reading test from a context-based perspective that proposes to link the different reading processes examinees engage in answering the test items to the actual context of reading activity. Using two questionnaires administered to the 126 student-participants and 29 teacher-participants in order to investigate the context of the DR Congo English state examination (ESE) and results from a mixed-methods study that has comprehensively investigated the construct validity of the same test, the results indicate that the ESE appears to have low validity as the test tasks do not appear to grip with the ESE context. The paper then suggests that the ESE tasks be adjusted so as to reflect the actual context of reading activity.
\end{abstract}

Keywords: construct validity, reading context, reading construct, context-based perspective, reading practices

\section{Preamble}

\subsection{Reading process: A cognitive activity perspective}

In conceptualizing reading as a process, many reading models consider text comprehension as a process where a reader must attempt and activate various cognitive processes in order to comprehend a text (Embretson \& Wetzel, 1987; Perfetti, 1997; Kintsch, \& van Dijk, 1978). In light of this conceptualisation, these processing models generally investigate the construct validity of a reading test by examining the students' use of strategies while they answer test items.

Methodologically, some of the studies that have adopted these models have investigated the construct validity of reading tests in terms of the hierarchical levels of reading construct by associating the specific cognitive processes examinees deploy to answer individual items with each level (Gao \& Rodgers, 2007; Grabe, 2009); therefore, classifying reading items in those that require examinees to process the text at higher level and those that require them to process the text at lower level. It is worth mentioning that lower level reading items include those that require examinees to encode lexis (Field, 2004), to parse sentences through an analysis of the grammatical constituents and an identification of the different syntactic relations (van Gompel, 2007), and to interpret clauses semantically by integrating the information in the sentence as a whole (Haberlandt \& Graesser, 1985). On the other hand, higher level reading items include those that require the examinee to make text inferences through an integration of the information provided in the text with the information that he/she already knows (Kintsch \& van Dijk, 1978), to build a text mental model by identifying text main ideas and by relating them to his/her background knowledge so as to construct some hierarchical structure of the information in the text (Kintsch \& van Dijk, 1978); as well as to create the text by determining which pieces of information are central to the meaning of the text (Weir \& Khalifa, 2008a, p. 7). Studies that have adopted this hierarchical-level taxonomy to validate the reading construct (see van Steensel, Oostdam \& van Gelderen, 2012; Rouet, Vidal-Abarca, Erboul, \& Miligo, 2001) have generally suggested that test items that require examinees to process the text at a higher level (text level) are more cognitively demanding than those that require examinees to process the text at lower level (sentence/paragraph level). More specifically, these studies have reported that 'low-level questions' are generally easy as they require examinees to read at sentence and/or paragraph level by quickly searching for text information at the level of text micro-propositions. On the contrary, 'high-level questions' are generally difficult as they require examinees to read at 
text level by focusing on text macro-propositions and by attempting to generate more connections between their knowledge and text information.

On the other hand, other studies have examined the reading construct by adopting a more sophisticated approach that operationalizes the reading construct on a four-cell matrix with careful reading and expeditious reading that can be conducted at both global level and local level (Weir \& Khalifa, 2008b; Weir, Hawkey, Green, \& Devi, 2008; Sarojani \& Krishnan, 2011). These studies have suggested that test items that require careful reading of the text appear to be more cognitively demanding than those that require expeditious reading of the text (Weir \& Khalifa, 2008b) on the ground that careful reading items appear to require a frequent combination of strategies as the examinee must extract complete meanings within or beyond sentences right up to the level of the entire text so as to construct the text macrostructure (Weir \& Khalifa, 2008b; Katalayi \& Sivasubramaniam, 2013). On the contrary, expeditious reading items appear to require less frequent combination of strategies as they involve a quick, selective and efficient reading to access needed text information (Weir, et al., 2008; Author, 2013).

In sum and spirit, the cognitive perspective on reading assessment suggests that it is possible to link particular reading items to specific sub-skills that they are said to tap into (Song, 2008; Embretson \& Wetzel, 1987; Gao \& Rodgers, 2007). Although validation studies that have adopted this perspective have incorporated relevant cognitive theories in assessing the reading construct, thus providing useful information on examinees' performance on the reading test, they nevertheless appear to have ignored to link the critical features of these cognitive theories to the specific testing context so as to reveal the meaningful cognitive processes in a particular test context. Methodologically, these models have used some current methods that help to understand how examinees complete test tasks such as protocol analysis and task analysis. However, these models appear to rely heavily on psychometrically driven methodologies such as factorial analyses and linear regressions (Young, 2008; Freedle \& Kostin, 1993) whose results hardly reveal the interaction between the different processes that are actually involved in answering the individual test items and the actual context of reading that is expected to clarify the particular test domain.

\subsection{Reading process: A social activity perspective}

The constructivist epistemology conceptualizes learning as a process of constructing personal meanings in social contexts (Vygotsky, 1978). Therefore, learners' emotional investment affects both the learning and the assessment processes. This is to suggest that the understanding of learners' characteristics and their influence on both learning and assessment can provide a useful ground for understanding learners' performance on reading tests. In light of this stance, the social activity perspective on reading posits that reading is a situated activity that takes place in a specific context with specific task demands (Bloome, 1985; Knoester, 2010; Sivasubramaniam, 2004; Katalayi, 2014). Therefore, the social context within which students read influences their reading behaviours by determining how they engage with reading tasks and the cognitive processes they internalize from and for reading.

In the context of reading in a second/foreign language, one route taken by the studies that have adopted a social activity perspective on reading has been the understanding of the socio-contextual variables that influence reading activity; and therefore impact on reading performance. One of these socio-contextual variables is the students' individual characteristics. Citing O'Sullivan (2000), Weir (2005) argues that students' physical and physiological characteristics (age, sex, short-term ailments), their psychological characteristics (personality, memory, cognitive style, motivation, emotional state), and their experiential characteristics (examination preparedness, experience with the test) affect their reading performance. Some studies have suggested that students' motivation for reading impact on their reading performance. Mucherah and Yoder (2008) found that students with high motivation for reading successfully read challenging materials, while those students with low motivation had difficulty approaching the same materials. On their part, Taboada, Tonks, Wiogfield, and Guthrie, (2009) found that reading motivation explained a substantial proportion of variance in reading performance, while Lau (2009) reported that reading motivation significantly contributed to the prediction of reading comprehension growth. Furthermore, other studies have suggested that positive attitudes towards the test can produce beneficial effects while negative attitudes can erode confidence and negatively impact on reading performance. Murray, Riazi and Cross (2012) found that candidates with negative attitudes towards the test due mainly to personal experiences and feelings as well as the impact of other people, notably teachers and other candidates unsuccessfully attempted the test tasks.

Apart from the individual characteristics of the students, other social-contextual factors that influence students' performance on reading assessments include teachers' qualification and experience, their motivation and commitment for teaching, their involvement in in-service training; to name only few. Harris and Sass (2001) found that teachers' in-service training positively correlated with teacher productivity; while Samupwa (2008) found that teachers who were regularly 
subjected to in-service training showed significant changes in behavior in both classroom and administrative work. On their part, Jahangir, Saheen and Kazmi (2012) indicated that teachers' in-service training brought significant changes in their perceptions of the teaching profession as they found that some teachers with negative perceptions of teaching profession changed their views and behaviours (personality, knowledge, and commitment skills) after they had participated to different training sessions.

Furthermore, the issue of the availability and quality of reading resources has been found to impact on reading performance. Research confirms the central role of an adequate supply of good quality textbooks in improving student performance; especially in the poorest countries where the provision of textbooks of good quality can counter-balance the problems of poorly trained teachers and lack of basic facilities in schools (Bukenya, 2005; Lewin \& Stuart, 2003). Furthermore, literature suggests a positive relationship between textbooks quality and availability and student achievement in reading. Greaney (1996) found a strong relationship between classroom collections of primary reading books and student performance on reading tasks; while Elkin and Lonsdale (1997) reported that students who were in schools with a library outperformed students who were enrolled in schools without a library.

In sum and spirit, the social activity perspective on reading premises that the whole range of aforementioned factors affect what one reads and how well he/she reads. Therefore, this perspective on reading can be useful to the reading assessment researcher by helping him/her understand students' reading behaviours by linking the different processes that students engage in answering the test items to the actual context of reading activity.

\section{Scope, Aim and Significance}

This paper examines the construct validity of the DR Congo English state examination, a high stake multiple-choice reading test administered to final year secondary school students as a subtest of the national test for certification. The aim is to evaluate the construct validity of this test from a context-based perspective by evaluating the extent to which the test tasks grip with the specific test context.

By examining the reading construct from a context-based perspective, the insights generated by this study can be gainfully deployed in the educational practice of reading assessment, and they can be used by reading assessment researchers to inform their validation studies. The study is particularly important in the Congolese context where literature points to inadequate and deficient descriptions of reading assessment practices. Therefore, the findings are meant to serve English state examination (ESE) developers to design a test that will include tasks that are adjusted to the actual context of reading activity that occurs in a French-dominated linguistic landscape with an infinitesimal presence of English in intra-national transactions and in public display (Kasanga, 2012).

\subsection{Research questions}

In order to examine the construct validity of the DR Congo English state examination from a context-based perspective, we propose to address the following two questions:

- What is the actual context of the DR Congo English state examination?

- To what extent the ESE tasks come to grip with the ESE context?

The answer to the first question aims to provide a description of the actual context of the ESE. On the other hand, the answer to the second question is expected to determine the extent to which the degree of complexity of ESE tasks is proportional to the actual test context.

\section{Method}

\subsection{Participants}

In order to gather data relating to the context of the ESE, this paper is conducted with 126 Grade 12 students (henceforth called student-participants) who were in the final year of secondary school and who were preparing for writing the national test and 29 English language teachers (henceforth called teacher-participants) who were teaching English in Grade 12.

\subsection{Instruments}

In order to investigate the social context of reading practices in the DR Congo, the paper uses two contextual 
questionnaires administered to the 126 student-participants and 29 teacher-participants. These two questionnaires are informed by theoretical and empirical insights on the social perspective on reading assessment (Katalayi, 2014; Mucherah \& Yoder, 2008; Harris \& Sass, 2001; Murray, Riazi \& Cross, 2012; Lau, 2009). The questionnaire administered to student-participants investigates four variables; including (1) their motivations for reading, (2) their experiences with the ESE, (3) their attitudes towards the ESE, and (4) the availability and quality of resources used in reading instruction. On the other hand, the questionnaire administered to teacher-participants investigates three variables; including (1) the classroom assessment methods they were using, (2) their participation in in-service training, and (3) the kind of resources they were using for teaching reading. The two questionnaires were both close and open in that each statement was followed by a number of suggestions the participants had to choose from and an empty box where they had to provide an explanation/reason of their choices.

As to students' motivation for reading, the paper draws on the methodological suggestions by Mucherah and Yoder's (2008) questionnaire on students' reading motivation, and Lau's (2009) Chinese Reading Motivation Questionnaire (CRMQ) on intrinsic motivation, extrinsic motivation and social motivation in reading and its relations to their performance. Therefore, the paper operationalizes this variable through questions that request student-participants to indicate and explain their frequency of reading at school and at home, their frequency of attendance to English classes, and the number of hours per week they preferred to learn English. As to students' experience with the ESE, the paper draws on Katalayi's (2014) methodological suggestion; and it operationalizes this variable by requesting the teacherparticipants to indicate their classroom assessment methods and explain their choices for these specific methods. As to students' attitudes towards the ESE, the paper is informed by Murray, Riazi and Cross (2012), Rasti (2009) and Han, Dai and Yang (2004)'s questionnaires on students' opinions, beliefs and feelings when they write a reading test; and it operationalizes this variable by asking the student-participants why they agree/disagree that all Grade 12 students must write an English test; that the ESE is just a way of failing the candidates in the national test; and that they sometimes do not feel to write the English test. Furthermore, in order to investigate teacher's participation in in-service training, the paper draws on Samupwa (2008), Jahangir, Saheen and Kazmi (2012), and Katalayi's (2014) methodological suggestions; and it operationalizes this variable by asking teacher-participants to comment on their participation to inservice training on English language teaching. Finally, in order to investigate the availability and quality of resources used in reading instruction, the paper draws from Katalayi's (2014) methodological suggestions; and it operationalizes this variable by examining the different reading resources both the student- participants and teacher-participants used as well as their evaluation of the quality of these resources.

On the other hand, in order to investigate the construct validity of the ESE items, the paper builds upon the results from a recent mixed-methods study that has comprehensively investigated the construct validity of the English state examination (Katalayi, 2014). This study was conducted in the same setting (Kananga, DR Congo) with participants sharing the same characteristics to those included in this study. Using a four-cell matrix reading taxonomy informed by Weir and Khalifa's (2008) model of reading, Katalayi (2014) used a concurrent strategies questionnaire and 50 multiplechoice reading test items that he administered to 496 Grade 12 secondary school students under normal testing conditions. The analyses consisted in computing the frequency of strategies the participants used to answer individual test items, as well as the mean item difficulty (mean ID) of test items so as to determine the complexity level of individual items. We wish to summarise the findings relating to the construct validity of the DR English state examination as reported by Katalayi (2014) as follow:

- The ESE tasks cover the whole range of reading construct by targeting all the processing levels;

- There is a preponderance of test items that target careful reading than those that target expeditious reading. However, test questions that target careful reading appear to be more difficult than those that target expeditious reading;

- Test items that require careful reading of the text appear to require a frequent combination of strategies as the examinees have to extract complete meanings within or beyond sentences right up to the level of the entire text so as to construct the text macrostructure. On the contrary, test items that require expeditious reading of the text appear to require less frequent combination of strategies as they involve a quick, selective and efficient reading to access needed text information;

- There is a predominance of test questions that require higher level processing than those that require lower level processing. However, test questions that require higher level processing appear to be more difficult than those that target lower level processing;

- While lower level questions mainly require examinees to read at sentence and/or paragraph level and recourse to their knowledge of grammar and/or vocabulary, higher level questions mainly require examinees to read at text level by attempting to generate more connections between their knowledge and text 
information.

\subsection{Analysis}

Although the two questionnaires were both close and open, the analyses targeted only the open part that included the participants' comments and explanations of their choices so as to gain deeper understanding of the context of the ESE. Therefore, we conducted the analyses in two main steps. The first step consisted of determining, from the range of choices the participants had selected, the different categories through a qualitative analysis of participants' written comments and explanations on the targeted issues. For example, three categories could be derived from the participants who commented on these three choices "I never read at home", "I rarely read at home", or "I usually read at home". After I had grouped the data in categories, the next step was to group the data within each category in different patterns. The likelihood of responses served to design and label the patterns. For instance, ten participants may have selected the choice "I never read at home". If three of them commented that he/she never read at home because of a lack of reading resources and four commented that they were not motivated in reading, while the three others referred to economic factors that prevented them from focusing on classwork at home, we therefore used these three response patterns to substantiate in each response category.

\section{Results}

\subsection{Students' motivation for reading}

We hypothesized that students with high motivation for reading frequently read at school and at home, they generally attend to English classes, and they tend to prefer more time to learn English.

\subsection{Reading frequency at school and at home}

Student-participants generally indicated that they rarely read in English at school and they never read in English at home. Those who indicated that they rarely read in English at school mentioned three main reasons. Firstly, the reduced number of hours per week for learning English as scheduled in the curriculum; secondly, the time they spent to copy the text in their notebooks; and finally the unavailability and incompetence of their teachers. The following excerpts can act as evidence:

\footnotetext{
Participant 1: First, I would say that even in class we do not really read. We just have 3 hours per week for English. I think we can read more if we have much time.

Participant 2: It takes 1 hour to copy the text that is written on the board. If it is a long text, when are we then going to read?

Participant 3: Our teacher is not good and he is too lazy. He takes much time to teach one text. He takes 2 sessions for writing the text on the chalkboard, 2 sessions for teaching vocabulary on the text; 2 or 3 sessions for teaching grammar on the same text; 1 or 2 sessions for text comprehension and discussion. After, he takes 1 session for dictation of a paragraph of the same text, and 1 session for essay writing. So, 1 text may take us 2 months.

Participant 4: My teacher rarely comes to teach us. When he comes, he takes so much time to tell us long stories about his personal life.

Participant 5: He [the teacher of English] has another job in a Pakistani shop where he serves as a translator. He rarely comes to class and whenever he comes to teach; he just sits down and asks us to copy the text.
}

However, student-participants who indicated that they never read in English at home mainly pointed to a lack of reading materials or to the little relevance of these materials to their needs, or again to their poor socio-economic conditions that do not permit them to read at home. The following extracts can illustrate this point:

Participant 1: I don't read in English at home because I don't have textbooks. I don't have anything to read.

Participant 2: I cannot spend my time to read a text that I believe I have copied it from the chalkboard with so many mistakes. I think it is important that we use printed texts. These texts can motivate us to read at home. When the teacher gives the book [teacher textbook] to one student and asks him to write the text on the board; the student does not pay attention to write correctly the text.

Participant 3: Those texts like 'the discovery of radium', 'Uncle Bernard in London', I don't understand them. I can't spend my time to read them at home. 
Participant 4: I don't have time to read at home. When I come back from school, I quickly rush to the market to sell some plastics in order to get some money to pay my studies.

\subsection{Students' attendance to English classes}

Student-participants' reports indicate that some regularly attend to English classes while others rarely attend to English classes. Those who regularly attend to English classes mention three main reasons: first, the growing importance of English in today's world life; secondly, the Congolese government's need to make English a second additional language together with French; and lastly, the different job opportunities the knowledge of English can provide them with. The following extracts can act as evidence:
Participant 1: English language is very important; the world is in rapid change and I must have at least basic knowledge of English.
Participant 2: There is nothing I can do today without some knowledge of English.
Participant 3: They [the government] want to make English a second international language beside French; so I must make effort to speak it.
Participant 4: They are telling us that at university, English is a compulsory subject in the first year of all faculties. They say that by 2015, students must be able to study different university subjects in French as well as in English. So, I must be prepared now.
Participant 5: What can you do today if you do not know English? To get a good job at all these United Nations organizations that are working here to bring peace in the country, you need to be skillful in English. So I want to be good at English to get a well-paying job in one of these organizations.

However, those participants who reported that they rarely attended to English classes mentioned two main reasons. First, teacher incompetence and lack of motivation for teaching; and then the perception that English is a difficult subject. Here are some illustrative reports from five participants:

\footnotetext{
Participant 1: I would like to be good at English; but it is since Grade 9 that I was disappointed by the English teacher. He was not a good teacher, he was not motivated and he was coming to teach rarely; then I lost all my motivation. Now, I feel I cannot catch up whatever I can do.

Participant 2: I don't see why I can regularly attend to English classes when my teacher [of English] rarely comes to teach.

Participant 3: Whenever we have English class, I just go out. This is a very difficult course. We don't have textbooks. The text is written on the chalkboard with so many mistakes. I don't feel any interest to attend the English classes regularly.

Participant 4: I think we need some materials for learning English. The use of these materials can motivate us to participate. I have lost all interest in English because of the way it is taught. I don't understand anything.

Participant 5: I don't know if in English the same word can be pronounced differently. Today our teacher pronounces a word in one way; tomorrow he pronounces the same word in another way; few days later another pronunciation. Then what can you learn from such confusion?
}

The teacher-participants' reports also provided additional information on the issue of students' participation in English classes. Some teachers indicated that their students did not regularly attend English classes because they perceived it as a difficult subject, or because they were not motivated for learning English subject. Nevertheless, these teacher-participants were of the view that the students who regularly attended English classes were good at English. The following explanations from three teacher-participants can support these views:

Participant 1: Some of my students don't regularly attend English classes. They repeatedly say that English is difficult; and this has as consequence poor proficiency level in English. Those who attend regularly are generally good at English. So I think the only way to be good at English is to attend English classes regularly.

Participant 2: Many students don't attend my classes. When I come in, I find that some students have left the class and they are in the school yard chatting. These students really don't have interest in the English course.

Participant 3: I am always concerned about my students' poor participation in my classes.

\subsection{Students' preferences for the time allocated for learning English}

According to the English curriculum (Programme National d'Anglais, 1988), the number of hours for teaching English is 5 hours per week in general schools, and 2 hours per week in technical schools. However, in the context of English as a 
foreign language where the classroom is the main setting for language learning, it can be hypothesized that students who are motivated can prefer more time to learn English while those who are less motivated can prefer a reduced time to learn English.

Student-participants comments and explanations suggest that they generally preferred a reduced time to learn English; a result of an overall negative attitude towards the English subject, as they believed it was a challenging subject, and their desire to allocate much learning time to other subjects they believed were more important than English subject. The following four excerpts can serve to illustrate these views:

Participant 1: Five hours are too much. It is also too boring. This time must be reduced to two hours as in other technical schools.

Participant 2: This is a difficult course. Five hours are too much; why not one or two hours; this will be enough.

Respondent 3: English subject is not as important as Maths. I think we need to reduce the time for learning English to two hours so that we can have much time to learn Math subject.

Respondent 4: English is not an easy subject. It is good that the time to learn it be simply reduced.

\subsection{Students' experience with the ESE}

Since the multiple-choice question is the assessment method used with the ESE, we hypothesized that teachers' use of this method in classroom assessment can help students get some experience with the ESE; therefore, they can have some familiarity with the ESE and write it with confidence. Teacher-participants' comments reveal that they generally prefer to use the open questions in classroom assessment on the ground that open questions are easier to design and that they best provide an appropriate indication of students' reading proficiency. The following extracts can act as evidence:

Participant 1: It is easy for me to construct open questions. I do not have time to construct multiple-choice questions.

Participant 2: It just takes me few minutes to design a test when I use open questions.

Participant 3: I use open questions because they give me the opportunity to know which students have understood the course materials and which ones have not understood. With the MCQ, you cannot tell that. Many students easily pass answers to their colleagues."

Participant 4: Open questions are good because they enable to check which students have understood the course materials and which ones have problems.

Participant 5: With open questions I am able to identify areas where my students have problems so that I can plan corrective tasks.

Participant 6: I never use the MCQ. They are very difficult to construct; and they need so much time. I think I am not prepared to do that. Also, they give an unfair advantage to weak students.

Participant 7: I never use the MCQ because I don't have samples of ESE test papers. The time I get some of these ESE papers, I will use them.

Participant 8: I don't like them [MCQ]. They don't provide a good indication of students' abilities.

Participant 9: I never use them. They are difficult to construct. Besides, they make students lazy.

Participant 10: They are easy to answer. I don't use them.

\subsection{Participants' attitudes towards the ESE}

We hypothesized that, although the ESE is a prescribed test, students with some negative attitudes towards the ESE may be reluctant to write this test. In scrutinizing student-participants' reports, we can state that they generally had some negative attitudes towards the ESE as they indicated that they should not be obliged to write this test, that it is a way of failing them in the national test; or again that it is not a fair test because it only tests reading comprehension and not other language skills. Those participants who believed that they should not write the ESE generally pointed their fear of not passing it as revealed in these two extracts:

Participant 1: Why do we need to write an English test when they know we are going to fail? Why don't they make it an optional subject? All of us don't need English. How many of those who teach English have gone to an English country? We can live without this language, and they don't need to make it a must.

Participant 2: It would be good for us not to write the English test. We can just study English as a school subject; but not write it.

However, those participants who were of the view that the ESE is a way of failing them in the national test provided 
as main explanation the fear to fail this test, as this failure might result either in not obtaining the national certificate or obtaining it with low mark that could not enable them to have direct access to university. The following three extracts can support this point:
Participant 1: I am sure I am not going to get any marks in this test [ESE]. I am working hard in other subjects to catch up. I'm afraid I may not get my certificate with good marks and be denied to start university by next year.
Participant 2: They know that English is difficult; but they have included nine questions [9 percentages] for the English test. We are going to fail.
Participant 3: They know that most students are not good at English; and that we do not like it. Still, they design exams that are very difficult. This is to make us fail.
Finally, those participants who believed that the ESE must test not only reading but also other skills argued that reading is not the only skill they needed to acquire while learning English and that other skills should be also tested; and that reading comprehension questions are generally more difficult than questions testing other language skills and aspects. The following comments from three participants clarify these views:
Respondent 1: Why only reading? It is as if reading is the only thing we must know.
Respondent 2: If the ESE includes sections of questions on grammar and vocabulary; we will be able to pass it quite easily. But reading [comprehension] questions are difficult because you cannot understand the text the way it is written. You can have your understanding and when you look at alternatives you choose one you think relates to your understanding; yet this is a wrong answer. But with a question on grammar, we all understand it in the same way. It is good to include other questions on grammar and vocabulary.
Respondent 3: I want the English test to include also questions on grammar and vocabulary; and not only on text comprehension.
Furthermore, teacher-participants' reports suggested that the ESE must not only assess text comprehension, but they should also assess the other skills in order to promote language proficiency in the learners; or that the actual focus on reading has resulted in a washback effect in English language teaching. The following are two excerpts that support these views:
Respondent 1: Why do we need to reduce English proficiency to reading comprehension? It is as if other skills are of no use. I think other skills must be tested to ensure that students are capable to be competent in English.
Respondent 2: You see what happens now. Other skills are neglected and even in course planning, these other skills deserve no attention.

\subsection{Reading resources}

Reading performance largely depends on the availability and quality of reading materials. An analysis of studentparticipants' comments on the kind of reading materials they read and their assessment on these materials suggest an abject paucity of reading materials as well as poor quality of the few existing materials.

Respondent 1: What am I going to read? I don't have textbooks or books. What can I read? I don't know why the educational authorities do not provide the school with textbooks for English like what happens for French where we use a textbook. It is as if English is not important.

Respondent 2: One of our classmates writes the text on the board; and this is with many spelling mistakes. So I cannot spend my time to read a text that I know is written with many spelling mistakes.

Respondent 3: We do not read frequently at school; why do I need to read at home? I am not interested in reading at home.

Respondent 4: I prefer to use my time to read the accounting course; I don't have time to read English. This is not my language, and I don't need to know it. Where shall I go with English?

Furthermore, teacher-participants' reports reveal that they did not have necessary reading resources; or in case these existed, they were not enough to be used by all the learners. The following excerpts can illustrate these two reasons:

Respondent 1: Since I have been teaching English, the school does not have textbooks. I have managed to photocopy some texts from 2 [two] textbooks and I have to write then on the chalkboard for the students to copy in their notebooks. Respondent 2: We do not have a school library; we do not have internet connection at school; where can I get the text? I have my textbook but my students do not have any copy; so I have photocopied some texts I have found good for students. Photocopied texts are the only one reading material I use in reading classes.

Respondent 3: There is huge problem of textbooks. What I do is to search for some relevant materials from technical brochures and magazines and I make some copies of these materials. This is not easy because the majority of students cannot afford these photocopied texts. But at least, these texts have the advantage to provide the learners with visual 
support for reading.

Respondent 4: My school has only five (5) copies of the textbook. Yet, I have 53 students in my class. It becomes difficult to use these five copies in reading classes. The only solution I have is to ask one student to write the text on the board and the other students to copy the text from the board. This is not without consequence. It takes so much time to complete writing the text and also it is too demotivating as some students just refuse to copy the text from the board.

\subsection{Teacher in-service training}

An investigation of teacher's participation in in-service training helps to gain additional understanding on the context of English language teaching in general and students' performance on the ESE in particular. We hypothesized that when inservice trainings are regularly organized for teachers, teachers' participation to these trainings contributes to improve their quality; therefore, this contributes to students' achievement. An analysis of teacher-participants' comments on this issue reveals that all of them expressed their unhappiness at the lack of training sessions organized for English teachers. They believed that such a lack was detrimental to teaching profession as they were not updated with new developments in teaching. One respondent made this comment:

To the best of my knowledge, since 2001 when I graduated and started teaching English; there has never been any training organized for English teachers who are currently practicing. How can teachers keep on with new developments in language teaching? Everything I know of teaching English is what I had learned at university.

Furthermore, participants believed that continuous training, especially in an English speaking country, was important as it is likely to enable teachers who have been trained to teach in an environment where English is not spoken outside the classroom to familiarize themselves with how the language is actually used by people who speak it. One respondent who espoused this view made this comment:

English is not the language used in this country. It is important that those who teach it be regularly trained. This training programme may focus on sending teachers for some time to an English speaking country even those which are neighbor to us like Zambia, Tanzania or Uganda. This may give them the opportunity to learn how language is actually used. Sometimes we just teach bookish English and not actual English; and this does not benefit to the learners.

Of utmost importance in teachers' in-service training is the issue of methods to be used for teaching English. Some respondents elaborated on this issue by complaining about the consequences of lack of in-service trainings. According to these respondents, one of these consequences is the actual confusion in the use of teaching methods by English teachers. The following extract is an argument developed by one respondent who was of this view:

I have been teaching English since 1980. Since then, I remember having participated in training sessions only two times. The first time was in 1984 when the British Council in Kinshasa organized a training session on the communicative approach to language teaching. The second time was in 1986 when the Peace Corps came to organize a seminar on the teaching of literature. That is all. The past 20 years no seminar has been organized. This has a big consequence on the use of teaching methods. There is a big confusion in our country depending on where you completed your studies. Some teachers pretend they have been better trained because they use the communicative approach. Others repeatedly support that the audio-lingual approach is best especially in situations like our country where the communicative approach cannot fit because of lack of appropriate resources. Still others support the direct method and they say it produces good results. Some even still use the Grammar Translation method, especially in technical schools. Myself I usually support that I don't teach the method, I teach the language. If there were regular seminar organized for teachers, we could not have this confusion. We could know what we are all expected to do.

\section{Discussion}

This paper aimed to examine the construct validity of the DR Congo English state examination from the context-based perspective by describing the specific context of this test and by evaluating the extent to which the test tasks come to grip with this context. The description of the ESE context can be summarized as follows: First, students appear to be less motivated for reading, and this is reflected in low reading amount at school and at home, low attendance to English classes and their preference to learn English in lesser time than the time planned for learning English. In light of this finding, we wish to highlight the following three observations: First, students with low motivation may have problems to successfully read test materials, especially if these materials are less appropriate. This observation appears to chime in Mucherah and Yoder (2008)'s finding when they reported that students who had high motivation in their reading successfully read challenging materials, while those students who were not highly motivated had difficulty approaching the same materials. Secondly, students' low motivation for reading may result (and sometimes is the result of) in low 
reading amount at school and at home. This relationship was established by Lau (2009) who found that students' motivation was mostly strongly related to their reading amount; suggesting that the more one reads the more motivated one can become. Lastly, students' participation in reading classes appears to be associated with their reading motivation; an association suggested by Lau (2009) when he found that students with negative motivation for reading were found to be reluctant to participate to reading classes.

Secondly, students appear to have negative attitudes towards the ESE as the study participants indicated that they felt and/or believed that they must not write the ESE as this test is perceived to be a way of failing them on the national test; and that the ESE is not a fair test since it is based only on text passage comprehension by neglecting other language skills. Furthermore, the participants appear to have preference for a reduced number of questions and number of alternatives to be included in the ESE. As evidenced by research, positive attitudes towards the test can produce beneficial effects while negative attitudes can erode confidence and potentially impact negatively on performance (Murray, Riazi \& Cross, 2012; Rasti, 2009, Han, Dai \& Yang, 2004).

Thirdly, the study findings indicate that, although the multiple-choice method is the ESE method, the majority of teachers use the open questions as the main classroom assessment method on the ground that the multiple-choice method is difficult to construct or it does not properly evaluate the students' language ability. This finding suggests that students are less familiar with the ESE. Yet, research suggests that students' familiarity with the test is a factor that can impact on examinees' performance as Peña and Quinn (1997) found that learners performed significantly better on the familiar test tasks, and that the familiar tasks were more sensitive in differentiating learners who were developing from those who were struggling.

Fourthly, the study findings indicate that reading instruction is severely hampered by an abject paucity of reading materials for reading at school and at home. Besides, it is also hampered by the use reading materials of poor quality. Yet, the presence of the text and its quality are a critical issue in the in the context of reading in a foreign language as Greaney (1996) and Lonsdale (1997) found a positive relationship between textbooks availability and student achievement in reading and student performance on reading tasks. The poor quality of reading materials as revealed by the data suggests that students are exposed to reading materials that appear to be less relevant to their needs. Furthermore, the data have revealed that student-participants' lack of motivation for reading also comes from the content of texts they read in classroom reading instruction. Yet, research suggests that reading resources of good quality can impact on students' reading, their motivation for reading and their performance on reading tests as textbooks of good quality can counter-balance the problems of poorly trained teachers and lack of basic facilities in schools (Lewin \& Stuart, 2003; Bukenya, 2005).

Finally, the findings reveal a total absence of in-service trainings as well as continuous trainings for English teachers. Consequently, teachers are not able to keep abreast of new developments in teaching. Furthermore, the findings suggest a substantial degree of confusion in teachers' use of teaching methods. Yet, research suggests a positive relationship between teachers' in-service training and teacher productivity (Harris \& Sass, 2001), a positive relationship between in-service training and change in behaviors in both classroom and administrative work (Samupwa, 2008), a positive relationship between in-service training and teacher perceptions of the teaching profession (Jahangir, Saheen, \& Kazmi, 2012), a positive relationship between in-service training and positive behavior (personality, knowledge, and commitment skills) on the part of the teachers (Conco, 2004).

\section{Conclusion}

The synthesis of Katalayi's (2014) findings on the investigation of the ESE tasks indicates that the majority of ESE items target careful reading instead of expeditious reading; on the one hand and reading at global level (text level) instead of reading at local level (sentence and paragraph levels); on the other hand. Furthermore, Author found that items that required careful reading appeared to be more difficult than those that required expeditious reading; and items that required reading at global appeared to be more cognitively demanding than those that required reading at local level. In light of these two findings and considering the description of the specific context of the ESE provided in this paper, we are inclined to conclude that the ESE tasks do not appear to grip with the ESE context. This is to suggest that the degree of complexity of ESE tasks hardly takes into account the students' characteristics (motivation for reading, attitudes towards the ESE, experience with the ESE) as well as the conditions under which reading instruction occurs (reading resources, teachers in-service training). We believe that the closer ESE tasks are adjusted to the ESE context, the more valid the ESE. This is to suggest that reading context and reading construct are two interrelated concepts and that a context-based perspective on reading construct appears to be a relevant way for investigating the construct validity of a reading test as it can help understand that examinees' performance on test tasks is also influenced by the context of reading activity. Since 
validity is about the relevance of inferences made on the basis of test scores (Messick, 1989, Kane, 2011), in order to be construct-valid, the ESE test scores need to closely reflect the actual reading context by including more tasks that target expeditious reading and that require reading at lower level as such tasks appear to be less cognitively demanding than those tasks that target careful reading and that require reading at higher level. This insight is worth considering in conducting validation studies. By conceptualising validity in terms of the appropriateness and meaningfulness of decisions made on test scores (Messick, 1989; Kane, 2002, 2011), we need to acknowledge that appropriate and meaningful decisions can be made when the test includes tasks that are adjusted to examinees' characteristics as well as the conditions under which reading instruction occurs. Therefore, failure to consider this context in ESE design necessarily results in tests with low validity.

\section{References}

Bloome, D. (1985). Reading as a social process in a middle school classroom, in D. Graddol \& J. Maybin (Eds.), Researching language and literacy in social context (pp.100-130). Clevedon: Multilingual Matters Ltd.

Bukenya, M. (2005). Findings and recommendations of the NAPE Report: Levels of competency in literacy and numeracy of primary school pupils in Uganda. Kampala.

Conco, Z. P. (2004). How effective is in-service training for teachers in rural school contexts. Unpublished Master Thesis, University of Pretoria, South Africa.

Elkin, J., \& Lonsdale, R. (1997). Focus on the child: Libraries, literacy and learning. The Library Association, London.

Embretson, S. \& Wetzel, D. (1987). Component latent trait models for paragraph comprehension tests. Applied Psychological Measurement 11, 175-93.

Field, J. (2004). Psycholinguistics: the Key Concepts. London: Routledge.

Freedle, R. \& Kostin, I. (1993). The prediction of TOEFL reading item difficulty: implications for construct validity. Language Testing 10(2), 133-170.

Gao, L., \& Rodgers, T. (2007). Cognitive-psychometric modeling of the MELAB reading items. Paper presented at the annual meeting of the National Council on Measurement in Education, Chicago.

Grabe, W. (2009). Reading in a second language: Moving from theory to practice. New York: Cambridge University Press.

Greaney, V. (1996). (Ed.). Promoting reading in developing countries: Views on making reading materials accessible to increase literacy levels (pp. 148-163). Newark, DE: International Reading Association.

Haberlandt, K. F., \& Graesser, A. C. (1985). Component processes in text comprehension and some of their interactions. Journal of Experimental Psychology: General 114(3), 357-374.

Han, B., Dai, M., \& Yang, L. (2004). Problems with College English Test as emerged from a survey. Foreign Languages and their teaching, 179(2), 17-23.

Harris, D. \& Sass, T. (2001). The effects of teacher training on the teacher value added. Journal of Teacher Education, 51, 164-169.

Jahangir, S. F., Saheen, N., \& Kazmi, S. F. (2012). In-service training: A contributory factor influencing teachers' performance. International Journal of Academic Research in Progressive Education and Development, 1(1), 31- 38.

Kane, M. T., (2011). Validating score interpretations and use: Messick lecture, Language Testing Research Colloquium, SAGE: Cambridge.

Kasanga, L. A. (2012). English in the Democratic Republic of the Congo. World Englishes, 31(1), 48-69.

Katalayi, G. B. \& Sivasubramaniam, S. (2013). Careful reading versus expeditious reading: Investigating the construct validity of a multiple-choice reading test. Theory and Practice in Language Studies, 3(6), 877-884.

Katalayi, G. B. (2014). Fundamental validity issues of an English as a foreign language test: A process-oriented approach to examining the reading construct as measured by the DR Congo English state examination. Unpublished Doctoral Dissertation, University of the Western Cape, South Africa.

Kintsch, W.M., \& van Dijk, T. A. (1978). Towards a model of text comprehension and production. Psychological Review, 85, 363-394.

Knoester, M. (2010). Independent reading and the 'Social Turn': How adolescent reading habits and motivation relate to cultivating social relationships. Networks, 12(1), 1-13.

Lau, K. (2009). Reading motivation, perceptions of reading instruction and reading amount: A comparison of junior and senior secondary students in Hong Kong. Journal of Research in Reading, 32(4), 366-382.

Lewin, K., \& Stuart, J. (2003). The Multi-Site Teacher Education Research Project (MUSTER) DFID, London.

Messick, S. (1989). Validity. In R. L. Linn (Ed.). Educational measurement (3rd ed., pp 13-103). New York: American Council on Education, Macmillan.

Mucherah, W., \& Yoder, A. (2008). Motivation for reading and middle school students'

performance on standardized testing in reading. Reading Psychology, 29(1), 214-235.

Murray, J. C., Riazi, A. M., \& Cross, J. L. (2012). Test candidates' attitudes and their relationship to demographic and experiential variables: The case of overseas trained teachers in NSW, Australia. Language Testing 29(4), 577-595.

Peña, E. D., \& Quinn, R. (1997). Task familiarity effects on the test performance of Puerto Rican and African American children. Language, Speech, and Hearing Services in Schools, 28, 323-332.

Perfetti, C.A. (1997). Sentences, individual differences, and multiple texts: three issues in text comprehension, Discourse Processes 23 , 
337-355.

Programme National d'Anglais (1988) DEPS, Kinshasa.

Rouet, J. F., Vidal-Abarca, E., Erboul, A. B., \& Miligo, V. (2001). Effect of information search tasks on the comprehension of instructional text. Discourse Processes, 31(2), 163-186.

Samupwa, M. (2008). Teacher training and work behaviour. International Journal of Human Resources, 65, 88-98.

Sarojani, K. \& Krishnan, D. (2011). Careful versus expeditious reading: The case of IELTS reading test. Academic Research International, 1(3), 25-35.

Song, M. Y. (2008). Do divisible subskills exist in second language (L2) comprehension? A structural equation modeling approach. Language Testing, 25(4), 435-464.

Taboada, A. Tonks, S.M., Wiogfield, A. \& Guthrie, J.T. (2009). Effects of motivational and cognitive variables on reading comprehension. Reading and Writing, 22, 185-209.

van Gompel, R.P. (2007). Syntactic parsing, in G. Gaskell (Ed.), The Oxford handbook of psycholinguistics. Oxford: Oxford University Press.

van Steensel, R., Oostdam, R., \& van Gelderen, A. (2013). Assessing reading comprehension in adolescent low achievers: Subskills identification and task specificity. Language Testing, 30(1), 3-21.

Vygotsky, L. S. (1978). Mind in society: The development of higher psychological processes, (M. Cole, V. John-Steiner, S. Scribner, \& E. Souberman, Eds. \& Trans.), Cambridge, MA: Harvard University Press.

Weir, C.J., \& Khalifa, H. (2008a). A cognitive processing approach towards defining reading comprehension, Cambridge ESOL: Research Notes, 31, 2-10.

Weir, C.J., \& Khalifa, H. (2008b). Applying a cognitive processing model to Main Suite reading papers, Cambridge ESOL: Research Notes 31, 11-16.

Weir, C. J. (2005). Language testing and validation: an evidence-based approach. Palgrave, Macmillan.

Weir, C., Hawkey, R., Green, A., \& Devi, S. (2008). The cognitive processes underlying the academic reading construct as measured by IELTS. IELTS Research Reports, 9, 157-189

Young, J.W. (2008). Ensuring valid content tests for English language learners. R\&D Connections, 8, ETS Research and Development, Princeton, NJ.

\section{Appendix 1: Contextual Questionnaire Administered to Student-Participants}

Instruction: In this questionnaire, you are requested to tick the box that reflects your views. Then after, you have to explain your choice. 1. How often do you read in English at school and at home? Indicate your frequency of reading on a scale where 1=regularly, 2=sometimes, $3=$ rarely and $4=$ never

\begin{tabular}{|c|c|c|c|c|c|}
\hline \multicolumn{2}{|c|}{ Frequency of reading } & 1 & 2 & 3 & 4 \\
\hline 1 & At school & & & & \\
\hline 2 & At home & & & & \\
\hline
\end{tabular}

Comment on/Explain your choices

2. Which of the following sources for reading do you use at school and at home?

\begin{tabular}{|l|l|l|l|}
\hline \multicolumn{2}{|l|}{ Sources used for reading } & At school & At home \\
\hline 1 & Texts copied from the chalkboard & & \\
\hline 2 & Texts photocopied from textbooks & & \\
\hline 3 & Textbooks & & \\
\hline 4 & Magazines/newspapers/brochures & & \\
\hline 5 & Books/novels/plays & & \\
\hline 6 & Internet source & & \\
\hline 7 & No source & & \\
\hline
\end{tabular}

Comment on/Explain your choices 
3. How often do you attend English classes?
1. Regularly
2. Sometimes
3. Rarely
4. Never

\begin{tabular}{|c|}
\hline \\
\hline Comment on/Explain your choice \\
\hline
\end{tabular}

4. For each of the following statements, tick in the box that reflects your attitude to the ESE

\begin{tabular}{|l|c|c|c|}
\hline Statements / Assertions & $\begin{array}{c}\text { Agree } \\
\text { J'accepte }\end{array}$ & $\begin{array}{c}\text { Disagree } \\
\text { J'accepte pas }\end{array}$ & $\begin{array}{c}\text { Don't know } \\
\text { Je ne sais pas }\end{array}$ \\
\hline 1 All final year students must write an English test & & & \\
\hline 2 The ESE is just a way of failing the candidates to the national test & & & \\
\hline 3 & & & \\
\hline 4 I sometimes feel that I don't need to write the English test & & & \\
\hline 5 & I don't mind failing to the English test & & \\
\hline
\end{tabular}

\section{Comment on/Explain your choices}

5. How many hours per week will you like to study English?
1. one hour per week
2. two hours per week
3. three hours per week
4. four hours per week
5. five hours per week

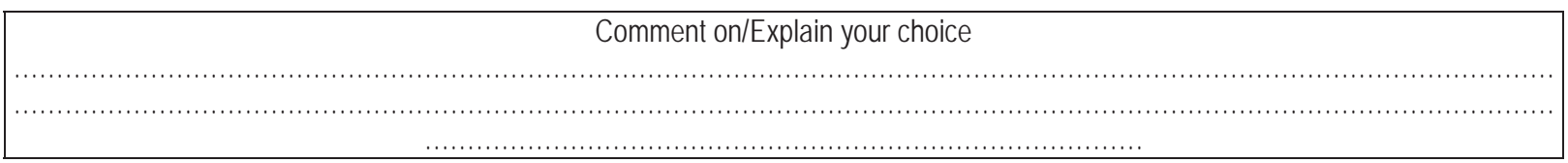

\section{Appendix 2: Questionnaire administered to teacher-participants}

1. How often do you use each of these methods to evaluate your students?

\begin{tabular}{|l|l|l|l|l|l|}
\hline \multicolumn{2}{|l|}{ Testing methods used } & Usually & Sometimes & Rarely & Never \\
\hline 1 & Open questions & & & & \\
\hline 2 & Multiple-choice questions & & & & \\
\hline 3 & Oral questions & & & & \\
\hline 4 & Essay questions & & & & \\
\hline 5 & Yes-No questions & & & & \\
\hline 6 & True-False questions & & & & \\
\hline 7 & Debates & & & & \\
\hline
\end{tabular}

Comment on/select your choices 
2. How often do you use the following sources of materials for your reading classes?

\begin{tabular}{|l|l|l|l|l|l|}
\hline \multicolumn{2}{|l|}{ Materials } & Usually & Sometimes & Rarely & Never \\
\hline 1 & Books & & & & \\
\hline 2 & Magazines & & & & \\
\hline 3 & Newspapers & & & & \\
\hline 4 & Internet sites & & & & \\
\hline
\end{tabular}

\section{Explain/Comment:}

3. How often do you participate to in-service training?

1. Usually 2. Sometimes 3. Rarely 4. Never 